

\title{
Vicisitudes económicas y sociales del oficial tallista en Lima en la primera mitad del siglo XVIl: pleitos y restricciones gremiales
}

\author{
Economic and Social Vicissitudes of the Official Carver in Lima in the First Half \\ of the Seventeenth Century: Lawsuits and Restrictions of the Carpenters Guild
}

Javier Chuquiray Garibay

Museo Pedro de Osma, Lima, Perú

javierchg@gmail.com

https://orcid.org/0000-0002-4690-3198

Recepción: 30/06/2020 | Aceptación: 18/09/2020

\begin{abstract}
Resumen
El presente artículo se ocupa de algunos aspectos económicos y sociales de los oficiales escultores y ensambladores que trabajaron en los talleres limeños, en la primera mitad del siglo XVII. La información que se proporciona proviene de documentación de época, como contratos de trabajo y otros documentos diversos, los cuales se presentan de manera sistematizada. En primer lugar, el texto se centra en las relaciones laborales entre el oficial y el maestro dueño del taller, las condiciones de trabajo, apuros económicos y pleitos derivados del ejercicio de su oficio. Y posteriormente, en el contexto de la corporación gremial al que pertenecían, mediante el estudio de dos casos sugestivos en concreto. Las relaciones profesionales entre ellos y de estos con el seno gremial, ayudan a comprender mejor los hechos escultóricos de la época estudiada.
\end{abstract}

\section{Palabras clave}

Lima

Siglo XVII

Oficiales

Escultores

Ensambladores

Gremio
Keywords

Lima

Seventeeth Century

Officials

Sculptors

Assemblers

Guild 


\section{Introducción}

En los estudios de arte virreinal de Lima, una manera de aproximarse a la figura del artesano tallista ha sido mediante el conocimiento de su trayectoria y de las obras que ejecutó, las cuales en ocasiones afortunadas han perdurado hasta la actualidad. Pero otra manera, desarrollada con menor extensión, ha sido mediante el conocimiento de su etapa formativa como aprendiz, en el taller del maestro, o de la labor desplegada como oficial, con trabajo especializado y remunerado'. En el caso de este último, su colaboración, hasta cierto punto anónima, terminaba por engranarse dentro de un proceso productivo dirigido o supervisado por el maestro dueño del taller. Hay que tener presente, sin embargo, que esta etapa profesional podía representar para el oficial no solo un ingreso para su sustento diario, de vital importancia, sino también una constante competencia para situarse mejor en el ejercicio de su profesión, en la que entraban en escena no solo sus propias condiciones sino también factores de orden económico y social del mundo que les tocó vivir.

Este tema en general fue tratado por el historiador Emilio Harth-Terré en un ensayo titulado Perspectiva social y económica del artesano virreinal en Lima². Las noticias inéditas, el análisis de documentos y los comentarios expuestos, desbrozaron un asunto poco explorado por la historiografía peruana, hasta entonces. A juicio del autor, cada uno de los puntos estudiados constituyó, sin embargo, solo un esbozo que podía ser ampliado en futuras investigaciones. En ese sentido, el presente texto recoge uno de los puntos planteados en ese ensayo, concerniente a las vicisitudes económicas y sociales del artesano virreinal, pero lo enfoca aquí al caso de los oficiales tallistas.

A diferencia del escrito de Harth-Terré, que puso mayor énfasis en el estudio de los albañiles y carpinteros, el presente texto se ocupa con preferencia de los escultores y ensambladores. Ellos cumplieron una importante actividad en la decoración de los altares de los recintos religiosos limeños, con sus retablos y esculturas, cuya demanda fue constante durante el Virreinato, y de forma especial e intensa en la primera mitad del siglo XVII. Se ha incluido también a los carpinteros, pues algunos de ellos

1. En la época y contexto aquí tratados, el término oficial usualmente refería a la categoría artesanal, entre el aprendiz y el maestro de un oficio determinado, y solo en contadas ocasiones para nombrar a este último. A menos que se indique lo contrario, en lo subsiguiente la palabra oficial se empleará para hacer mención estrictamente al grado artesanal intermedio. Por otra parte, el término tallista hará referencia a los que se dedicaron a la talla en madera, especialmente a los escultores y ensambladores.

2. Emilio Harth-Terré y Alberto Márquez Abanto, "Perspectiva social y económica del artesano virreinal en Lima," Revista del Archivo Nacional del Perú 26, no. 2 (1962): 353-446. Se sabe que el historiador Emilio Harth-Terré era el autor principal de los trabajos que publicaba junto con Alberto Márquez Abanto, quien colaboraba con facilitar la información proveniente de los archivos coloniales. 
tras formarse en dicho oficio llegaban a especializarse luego como ensambladores, como se verá más adelante ${ }^{3}$. En menor medida se hace mención de pintores y doradores, quienes coincidían con los anteriormente mencionados, de manera singular, en la decoración de los retablos, a la cual aportaban con sus pinturas y aplicaciones de pan de oro. Por esa razón, no sorprende que existiera una estrecha colaboración entre sus talleres, en ciertos casos.

Aunque existe aún poca información publicada acerca del oficial tallista, con el análisis de la documentación disponible y el material inédito que se ha podido acopiar, puede brindarse de manera preliminar una sistematización de los hechos relacionados con algunos aspectos de su economía y el ambiente social en el que ejerció su oficio.

\section{El oficial tallista}

En general, cada actividad artesanal estaba regulada por unas ordenanzas dictaminadas por el seno gremial al que pertenecían, las cuales eran sancionadas por el Cabildo de la ciudad. Entre las varias estipulaciones que las regían, había especialmente una relacionada con la formación del artesano la cual debía darse en el obrador de un maestro agremiado. Se sabe que la corporación gremial reconocía una jerarquía formal, la cual distinguía tres estados del artífice: el aprendiz, el oficial y el maestro, de menor a mayor grado, respectivamente.

Con la firma de un contrato denominado a veces asiento, el alumno iniciaba la etapa de formación que todo artesano virreinal debía cumplir para dedicarse a un oficio determinado. En el taller del maestro recibiría los primeros rudimentos y también alojamiento, alimentación, vestido y asistencia médica, si cayere enfermo, hasta por quince días. Al final del periodo de aprendizaje, el pupilo sería evaluado mediante un examen de suficiencia para ascender al siguiente escalón; es decir, al grado de oficial. Si era promovido, el oficial examinado podía laborar a las órdenes de un maestro agremiado, que le abonaría a cambio un estipendio, mediante la firma de un contrato laboral, también

\footnotetext{
3. A diferencia de los escultores y ensambladores, cuyos talleres se relacionan más con la producción de imágenes y mobiliario religioso (sillerías, cajonerías, retablos, púlpitos, etc.), los carpinteros se relacionan con el campo de la arquitectura (techumbres, corredores, balcones, escaleras, etc.) y mobiliario doméstico. Sobre las actividades de los carpinteros en la arquitectura y mobiliario doméstico limeños, ver: Antonio San Cristóbal, La casa virreinal limeña de 1570 a 1687 (Lima: Fondo Editorial del Congreso del Perú, 2003), 2: 155-190; María Dolores Crespo Rodríguez, Arquitectura doméstica de la ciudad de los Reyes (1535-1750) (Sevilla: Consejo Superior de Investigaciones Científicas, Escuela de Estudios Hispano-Americanos, 2006), 101-132, 311-329.
} 
denominado a veces asiento. Ahora bien, si el oficial tenía la experiencia suficiente $y$, sobre todo, los recursos, podía solicitar rendir un examen para ascender al siguiente grado y convertirse en maestro. Llegar a ese estado implicaba que el artífice podía abrir taller propio y ejercer de manera pública; es decir, concertar obras directamente, formar aprendices, contratar oficiales $y$, además, la posibilidad de ser elegido miembro del gremio de su oficio.

\section{Ingreso laboral}

Para el desarrollo del presente estudio, se han revisado 11 contratos laborales firmados entre un maestro y un oficial. Del análisis de estos documentos, se han podido distinguir dos tipos de contrato, según la ganancia salarial de los oficiales: 1) a jornal y 2) a destajo. En el primero, la ganancia se determinaba por las jornadas de trabajo que cumplía al servicio del maestro; en el segundo, por la obra ejecutada. Hay mayor número de contratos firmados a jornal (8) con respecto de los segundos (3), y no se sabe si esto tuvo correlación con los hechos, pero debido a los diferentes términos con que se celebraron cada uno, se ha preferido tratarlos en dos secciones distintas.

\section{Contrato a jornal}

Por lo general, bajo este tipo de contratos se ajustaban jóvenes oficiales que recién habían superado el examen de grado correspondiente. De acuerdo al promedio de edad con que culminaban la etapa previa de aprendizaje, podría decirse que se trataba de personas que no excederían la mayoría de edad que en aquel entonces era de 25 años. En estos convenios el tiempo de servicio era variable, entre los 2 años y medio y 1 año como mínimo, siendo este el de mayor recurrencia. Durante el periodo convenido, el oficial se comprometía a asistir al maestro en lo tocante a su oficio, sin mencionarse alguna tarea específica a realizar.

La remuneración del artesano virreinal era compleja tanto en los medios, cantidad y formas de pago. Con respecto a los oficiales artífices, ellos percibían dinero y, habitualmente, alimentos; en ciertos casos, ropa e incluso alojamiento ${ }^{4}$. Según los datos

\footnotetext{
4. Francisco Quiroz Chueca, Artesanos y manufactureros en Lima colonial (Lima: Banco Central de Reserva del Perú; Instituto de Estudios Peruanos, 2008), 92-93; Harth-Terré y Márquez Abanto, "Perspectiva social," 390-400.
} 
que se han recopilado, el salario que percibía el oficial por jornal en promedio era de 10 reales, y el salario anual de 300 pesos $(8)^{5}$. La entrega del dinero podía efectuarse 0 bien a plazo fijo, ya sea cada día, mes o año, o bien según lo fuere requiriendo el oficial -aunque podría darse también una combinación de ambas-, siempre conforme a las jornadas de trabajo que hubiere cumplido. En algunas ocasiones se podía negociar un adelanto; aunque lo normal era que se le pague por los días trabajados.

Los contratos contemplaban ciertas contingencias que se podían presentar en el transcurso del convenio, como posibles ausencias del oficial o un despido. Ante esas circunstancias, ambas partes se amparaban en unas cláusulas específicas, las cuales se comentarán más adelante. El acuerdo se acreditaba con la fe del escribano público. De ese modo, el maestro y el oficial se sometían a las sanciones correspondientes en caso de incumplimiento.

Debido a la naturaleza de estos contratos, el asunto de que se trató con mayor relevancia fue la asistencia del oficial en la tienda del maestro. En caso de ausencia, ya sea por enfermedad u otro impedimento, se le descontaría de su salario. Pero el oficial tenía la opción de subsanar dichas faltas compensándolas con jornadas extraordinarias de trabajo, al final del periodo pactado. Así se lee en el convenio que firmaron el oficial Pablo Alonso, moreno libre, y el maestro ensamblador nazqueño Tomás de Aguilar, el día 25 de enero de 1634. Luego de convenir sobre el tiempo de trabajo y remuneración, Pablo Alonso se obligó a "que durante los dichos dos años ningún día de trabaxo le haré falta ni falla ni faltaré de trabaxar y los días que faltare se los pagaré y trabaxaré a el cabo de el tiempo". Para asegurar el cumplimiento de esta cláusula, luego se hizo la siguiente advertencia: "y si me fuere o ausentare de su casa y trabaxo del dicho Tomás de Aguilar por su autoridad o de la justicia me a de traer y sacar de a donde estuviere y apremiarme a que trabaxe con el suso dicho hasta que se cumpla los dichos dos años y las costas que en razón desto se le recresieren y lastare se las pagar" ${ }^{\prime \prime}$.

De acuerdo con la documentación disponible, se desprende que el oficial que se ausentaba de la tienda del maestro lo hacía no siempre por encontrarse indispuesto, sino en ocasiones para atender otros asuntos. Esta situación, por ejemplo, puede advertirse

5. Harth-Terré y Márquez Abanto, "Perspectiva social," 390-391. Si estas cantidades de pago equivalen a lo mismo, entonces podría decirse que en promedio existían 240 días de trabajo efectivos, y el resto de días serían domingos y feriados. Este número de días laborales entra en el rango propuesto por Quiroz Chueca, Artesanos y manufactureros, 101. Por comodidad expositiva, en el presente artículo se hace referencia al valor monetario del peso, 0 bien con (8) - cuando se trata de a 8 reales - 0 bien con (9) -cuando se trata de a 9 reales.

6. Asiento, Lima, 1634, protocolo notarial 1875, folios 48v.- 49v., Archivo General de la Nación del Perú (en adelante AGN), Lima. 
con mayor claridad en el contrato firmado el día 16 de enero de 1626, entre el oficial Hernando de Josephe, mulato libre, y el maestro de ensamblaje y talla Pedro de Noguera, natural de Barcelona. Josephe se comprometió a trabajar durante un año en la tienda de Noguera, y anotaba lo siguiente: "durante el dicho año me obligo de no trabaxar en otra tienda ni ausentarme de la del dicho Pedro Noguera y si lo hiciere quiero y consiento que el dicho Pedro de Noguera me saque de la tienda donde trabajare judicial o extrajudicialmente"7.

Al parecer, a veces no bastaba solo con el uso de la fuerza para que el oficial cumpliera con lo acordado, y en consecuencia se preveían medidas más coercitivas como la registrada en otro contrato firmado por los mismos artífices años después, el día 27 de febrero de 1639. En esa oportunidad el oficial convino con el maestro Pedro de Noguera en trabajar a su servicio por dos años, tiempo durante el cual "[Josephe] se obligó de no ausentarsse y si se ausentare quiere ser apremiado por todo rigor de derecho y prisión al cumplimiento dello"8. A juzgar por las medidas preventivas que se adoptaban en este tipo de contratos, el ausentismo de los oficiales en los talleres debió de producirse con cierta frecuencia, aunque se ignoran las razones que lo originaban, más aún cuando había un contrato de por medio.

\section{El salario}

Es importante recordar que la ocupación del oficial en el taller del maestro le impedía emplear su tiempo en otra cosa que no fuera estar al servicio del maestro contratante, al menos en los días hábiles. Esto quiere decir, como se ha visto, que el oficial no podía trabajar en otra tienda. En ese sentido, si solo se considera el salario a jornal que ganaba un oficial, en algunos casos podría parecer insuficiente para cubrir sus necesidades básicas diarias; sin embargo, hay que tomar en cuenta que ellos percibían por lo general, adicionalmente, bienes y/o servicios que les permitiría disponer del dinero ganado para otros gastos.

Por ejemplo, Asensio de Salas prometió pagar al oficial ensamblador Francisco de Sosa la cantidad de 80 pesos (8) por un año de servicio en su taller, como consta en el concierto

\footnotetext{
7. Concierto, Lima, 1626, protocolo notarial 1998, folios 70-70v., AGN, Lima. Citado en: Antonio San Cristóbal, La Catedral de Lima. Estudios y Documentos (Lima: Museo de Arte Religioso de la Catedral de Lima, 1996), 283-347.

8. Concierto, Lima, 1639, protocolo notarial 1604, folio 104-104v., AGN, Lima. Citado en: San Cristóbal, 305.
} 
que ambos firmaron el día 1 de octubre de $1640^{9}$. Podría pensarse entonces que Sosa solo tendría 1 real y 3/4 para cubrir sus gastos diarios de alimentación, lo cual no sería suficiente pues el costo de alimentos podía fluctuar entre 2 y 4 reales en la época tratada ${ }^{10} ;$ no obstante, la remuneración comprendía servicios como alimentación y alojamiento, e incluso ropa limpia, por los cuales Sosa no tenía por qué preocuparse.

Ciertamente, no en todos los casos el oficial accedía a un servicio tan básico como el de la alimentación. Si no se considera eso uno podría suponer que la paga de 300 (8) pesos que le daría el maestro Josephe Pizarro al oficial ensamblador Salvador Fernández, sería el dinero que dispondría efectivamente por el año de trabajo que efectuaría en la tienda del maestro (desde el día 6 de febrero de 1650). Sin embargo, Pizarro no le proporcionaría alimentos, aunque sí alojamiento. De ese modo, Fernández debió asumir el coste alimenticio mediante un descuento de su salario a razón de 3 pesos (8) por semana, como quedó estipulado, lo que reduciría notablemente su ganancia a poco menos de la mitad. A pesar de eso le quedaba cierto margen para otros gastos" ${ }^{11}$.

Fuera de eso, puede decirse que algunos oficiales ganaban más dinero que otros. En los ejemplos que siguen, aunque en diferente fecha, cada oficial carpintero percibía una remuneración que consistía en un salario fijo más alimentación, que era proporcionada todos los días de trabajo. Uno de ellos, Pablo Alonso (moreno libre), ganaba 10 reales por jornal en 1634, que era más o menos el promedio en la época tratada; el otro, Tomás de Aguilar, ganaba por encima de ese promedio: 2 pesos (8), o sea 16 reales por día de trabajo, durante el año de $1617^{12}$. A propósito de lo dicho, habría que señalar que la extracción étnico-cultural de los artífices tenía poco que ver con la cantidad de dinero

9. Asiento, Lima, 1640, protocolo notarial 1878, folio 1107v.-1109, AGN, Lima.

10. Los estudiosos Harth Terré y Márquez calcularon que el gasto de alimentación por día era de 3 reales y medio a fines del siglo XVI, Harth-Terré y Márquez Abanto, "Perspectiva social," 398. A continuación, se da a conocer información relevante al respecto. El oficial dorador Antonio del Corral acordó, entre otras cosas, que durante el año de trabajo en el obrador del maestro Juan de Arce, este le debía "dar de almorzar comer y senar en su casa los días de trabajo, y los días de fiesta me a de dar dos rreales para comer": Concierto, Lima, 1639, protocolo notarial 1604, folios 839v.-840v., AGN, Lima. Asimismo, Pedro de Noguera le entregaría a Hernando de Joseph 4 reales cada día"para su sustento": Concierto, Lima, 1639, protocolo notarial 1604, folio 104, AGN, Lima. Mientras que Salvador Fernández recibiría de Joseph Pizarro 3 pesos (8) cada semana, igualmente para su sustento, lo que serían poco menos de 3 reales y medio por día: Concierto, Lima, 1650, protocolo notarial 386, folios 343-344, AGN, Lima. Al parecer, el monto de 3 reales y medio también se mantenía más o menos en la primera mitad del siglo siguiente.

11. Ver cita 10, último documento. Harth-Terré y Márquez apuntaron que un oficial dorador pagaba 12 reales al mes por un aposento, en el año 1634; y un oficial carpintero, 20 reales al mes, en el año 1649. Harth-Terré y Márquez Abanto, "Perspectiva social," 393.

12. Concierto, Lima, 1617, protocolo notarial 1799, folio 5-5v., AGN, Lima. No se tienen más noticias de Pablo Alonso como carpintero, 0 ejerciendo alguna otra actividad. En cambio, el nazqueño Tomás de Aguilar (1596-1666) ascendió al grado de maestro y se dedicó preferentemente al oficio de ensamblador, con una extensa y destacada trayectoria en la ciudad de Lima: Antonio San Cristóbal, "El Ensamblador Tomás de Aguilar, natural de Nazca (1596-1666) y el Retablo-Sepulcro del arzobispo Arias de Ugarte," Histórica 38 (1993-1995): 177-215. Este es uno de los casos ejemplares de maestros carpinteros que se especializaron luego en el oficio de la ensambladura de retablos. 
que podían ganar o generar, la cual dependía más bien de su capacidad y cualidades que mostraban en un oficio determinado ${ }^{13}$. Los oficiales que percibían para la época salarios por encima del promedio, como Hernando de Josephe o Tomás de Aguilar, seguramente cumplían con dichas condiciones. Aun así, la cantidad de dinero que podían recibir no les eximía de pasar apuros económicos o verse envueltos en líos judiciales, los cuales parecen haber sido los gajes del oficio, como se comentará más adelante.

\section{Formas de pago}

Un factor importante a tener en cuenta cuando se analiza la economía del oficial es la disponibilidad de su ganancia. En los contratos, algunos oficiales hacían constar que preferían cobrar a plazo fijo, como el dorador Andrés Rosales que concertó con el maestro Juan de Arce el día 6 de octubre de 1642. El trato fue por un año, que había empezado a correr pues ya estaba trabajando en el taller desde el día 25 del mes anterior. Se le pagaría la suma de 140 pesos (8), entregados "a el fin de cada quatro meses lo que montaren"14. Otros preferían disponer de su dinero como lo requiriesen. De ser ese el caso, en los conciertos se apuntaban frases como las siguientes: "como fuere trabajando", "como lo fuere ganando y pidiendo", o "como lo fuere causando y quiere menester". Estos enunciados dan a entender que el maestro administraba directamente el dinero del oficial que podía disponer de su salario según los "menesteres" que se le presentaren. Así ocurrió con el oficial escultor Juan de Yllescas, que asentó el día 10 de julio de 1630 con el maestro de arquitectura y escultor Pedro de Noguera. Yllescas se obligó a trabajar por un año en la tienda de Noguera, que le prometió pagar la cantidad de 300 pesos (8), según "como los fuere pidiendo para su menester y los demás pesos restantes cumplimiento a los dichos trescientos pesos a el fin del dicho año"15.

Como se ha dicho, el desembolso del dinero se efectuaba según las jornadas trabajadas, eso a menos que se haya gestionado un adelanto como lo hizo Simón de Monserrate y Cevallos cuando pactó con el maestro dorador Juan de Arce para trabajar en su tienda por un año, desde el 15 de enero de 1642. Arce se obligó a proporcionar a

13. Harth-Terré y Márquez Abanto, "Perspectiva social," 397. Aunque es cierto que, debido al estigma social de la época, el origen de los artífices determinó que se crearan una serie de normas gremiales restrictivas para el ejercicio del oficio a negros y a indígenas. Sin embargo, a pesar de esas prohibiciones, se cuentan con algunos ejemplos de ellos que alcanzaron incluso el grado de maestro. Este tema se desarrollará más adelante, en este artículo.

14. Concierto, Lima, 1642, protocolo notarial 68, folios 212v.-213, AGN, Lima.

15. Concierto, Lima, 1630, protocolo notarial 133, folio 324-324v., AGN, Lima. Citado en: San Cristóbal, La Catedral de Lima, 305. 
Monserrate alimentación (los días domingos y de fiesta incluidos) y pagarle su salario a plazo fijo a razón de 12 patacones "cada mes al fin de cada uno cumplido aviendo primero el susodicho [oficial] desquitado los treinta pesos de la dicha plata que así le tengo pagados adelantados"16.

\section{Contrato a destajo}

En cuanto a este tipo de contratos, existe una evidente diferencia entre los ejemplos anteriormente presentados y el que se presenta ahora, la cual está relacionada con el trabajo asignado y en la correspondiente forma de pago. En primer lugar, el propósito del contrato a destajo era la ejecución de una obra determinada cuya realización debía ceñirse el oficial a un modelo o "traza" que sería proporcionado por el maestro. De ahí que en este tipo de convenios se encuentre una descripción de la tarea solicitada o se remita a una "memoria", se anexe un diseño o modelo a seguir e incluso se requiera una evaluación del trabajo entregado. De esa manera, el suministro del salario del oficial iba a depender del avance y culminación satisfactoria del producto artístico, no tanto del tiempo que le demandare su ejecución.

Con respecto al estipendio, este consistía en un salario cuyo monto dependía de la tarea encargada. La paga se efectuaba según convenían las partes, o los plazos que dictaba el cliente. En el primer caso había cierta flexibilidad en la entrega del dinero, que lo administraba directamente el maestro dueño del taller. Por ejemplo, el 20 de febrero de 1642, el maestro ensamblador Asensio de Salas concertó con el oficial escultor Pedro Fernández de Cabrera para que le haga "un trono" y dos figuras de ángeles que se colocarían en un retablo que Salas estaba haciendo para el altar mayor de la nueva iglesia de la orden agustina, la cual se fundó bajo la advocación de Nuestra Señora de Guía y Copacabana. El oficial debía entregar la obra "en toda perfección" dentro del plazo de 3 meses, "y si antes lo acavare del dicho plazo lo a de rescebir [Salas] y por dello le a de dar y pagar ciento y veinte pesos de a ocho [reales]". Fernández arregló incluso un adelanto de 40 pesos (8) y percibir el resto de su salario "como lo fuere trabajando $[\text { la obra }]^{\prime \prime 17}$.

16. Concierto, Lima, 1642, protocolo notarial 1862, folio 19-19v., AGN, Lima.

17. Concierto, Lima, 1642, protocolo notarial 1821, folio 19-19v., AGN, Lima. Citado en: Rafael Ramos Sosa, "Retablos y esculturas: El salomónico en Lima, 1650-1710," en El triunfo del Barroco en la escultura andaluza e Hispanoamérica, coords. Lázaro Gila Medina y Francisco Javier Herrera García (Granada: Universidad de Granada, 2018), 397-422. 
Ahora bien, podía ocurrir que la paga al oficial procediera directamente de la paga que efectuaba el cliente al maestro, a quien usualmente se le remuneraba en tres partes: antes de comenzar, durante el proceso y una vez finalizada la obra contratada. Sin embargo, siempre existía la posibilidad de que el oficial dispusiera de su dinero antes de lo programado. Así se estableció en el contrato que firmaron el maestro escultor Martín Alonso de Mesa y el oficial ensamblador Antonio Vásquez, el día 20 de febrero de 1623. El oficial Vásquez se encargaría de terminar el retablo que el maestro escultor tenía concertado hacer para los mayordomos de la cofradía de la Pura y Limpia Concepción, cuya capilla estaba fundada en el convento de San Francisco. Vásquez recibiría su paga de 950 pesos (8) en tres partes, tal y como había pactado Mesa con los mayordomos de la cofradía. Pero se introdujo una condición que posibilitaba un adelanto de pago al oficial. En palabras del maestro escultor: "si yo le diere y pagare [a Vásquez] alguna plata a quenta de los dichos novecientos y cinquenta pesos eso a de cobrarme nos de los dichos mayordomos y de lo que dello recibiere de sus cartas de pago [otorgadas por Vásquez] en cumplida forma"18.

Las anotaciones en el margen de la escritura dan cuenta que el día 10 de abril del mismo año los mayordomos de la cofradía de la Concepción ya habían efectuado la primera paga al maestro sevillano, pero este aún no le había pagado al oficial lo que le correspondía. Enterados los mayordomos de tal situación, se le dio a Mesa solo una parte de la segunda paga, y decidieron que "no [ se ] le acuda con más plata al dicho Martín Alonso de Mesa hasta que cobre el dicho Antonio Vásquez lo que le debe". Al poco tiempo, el día 29 de abril, Vásquez recibió 300 pesos (8) de Fabián Gerónimo, que le pagó de parte del maestro escultor. El retablo debió de ser de gran envergadura e importancia, a juzgar por los testimonios de época como por la ornamentación que debía ostentar ${ }^{19}$.

18. Concierto, Lima, 1623, protocolo 771, folios 45-46, AGN, Lima. Citado en: Rafael Ramos Sosa, "Una escultura de Martín Alonso de Mesa, el San Juan Evangelista de la Catedral de Lima (1623) y otras noticias," Histórica 27, no. 1(2003): 196.

19. Bernabé Cobo, Historia de la fundación de Lima (Lima: Imprenta Liberal, 1882), 263-264; Antonio San Cristóbal, Nueva visión de San Francisco de Lima (Lima: IFEA; BCRP, 2006), 150. Se sabe que el día 19 de mayo de 1627 se instaló en él una imagen de la Inmaculada, hecha por el excelente escultor castellano Gregorio Fernández: Javier Chuquiray Garibay, "El escultor Pedro Muñoz y la impronta de Gregorio Fernández en su obra limeña," en Pinceles y gubias del Barroco Iberoamericano, vol. 7 de Universo Barroco Iberoamericano, eds. María de los Ángeles Fernández Valle, Carme López Calderón, e Inmaculada Rodríguez Moya (Santiago de Compostela: Andavira Editora; Sevilla: Enredars/Universidad Pablo de Olavide, 2019), 275-287. La construcción de este retablo había llamado la atención de otro artífice, el catalán Pedro de Noguera, prestigioso arquitecto y escultor de la época. Se sabe que el día 22 de septiembre de 1622, Noguera junto con el escultor Luis de Espíndola solicitaron a las autoridades de la cofradía de la Concepción hacer ellos el retablo, para lo cual ofrecieron rebajar el precio, fijado por Mesa, en 1000 pesos (8). Sin embargo, su solicitud no prosperó: Lima, 1622, cofradías, legajo 5, expediente 3, Archivo Arzobispal de Lima (en adelante AAL), Lima. Citado en: Ramos Sosa, "Una escultura de Martín Alonso," 196. Estas pugnas tendrían lugar especialmente a partir de la segunda década del siglo, cuando se instalaron en la ciudad una nueva generación de escultores y ensambladores españoles. 


\section{Vicisitudes económicas y sociales}

\section{Apuros económicos y pleitos}

El día 28 de mayo de 1642, el oficial ensamblador Hernando de Josephe estaba sin cumplir con una escritura de asiento que había firmado con el maestro mayor de arquitectura Pedro de Noguera. Aunque en el documento no se hace referencia con claridad al tipo de trabajo encomendado a Josephe, este había recibido 70 patacones a cuenta de ello. Tal parece que el oficial había abandonado el taller sin haber satisfecho el trabajo. Como consecuencia de ello, el oficial fue a prisión. Sin embargo, gracias a la fianza otorgada por el maestro ensamblador Asensio de Salas, fue puesto en libertad solo "por ocho días para ajustarse en ellos de quentas con el dicho Pedro de Noguera".

No se sabe cuáles fueron las circunstancias que motivaron a Salas a actuar como fiador de Josephe, aunque podría conjeturarse que su intención fuera que el oficial terminare trabajando en su obrador hasta que acabe de pagar la deuda, como venía ocurriendo con otro oficial en su taller ${ }^{20}$. Esto podría explicar por qué Josephe "se ausentó", una vez liberado de modo temporal. En ese escenario, con el oficial ausente, el fiador Asensio de Salas no tuvo otra opción que cancelar la deuda a Noguera (la cual se acordó finalmente en 30 patacones), no sin antes solicitarle que se aparte del pleito contra Josephe porque en adelante quería ocupar su lugar en la demanda contra su ahora deudor ${ }^{21}$.

Es difícil saber cuáles pudieron ser las motivaciones que llevaron a Josephe a abandonar el taller del maestro, más aún cuando había un contrato que cumplir. Sea la circunstancia que fuere, a continuación, se presentan otros documentos que pueden dar contexto a las vicisitudes económicas a las que estaban expuestos los oficiales artífices, en el ejercicio de sus oficios.

20. El día 23 de febrero de 1642, el oficial Lucas Alcalde se obligó a pagar 50 pesos (8) al maestro ensamblador Asensio de Salas, por un préstamo que le hizo "por hacerme amistad y buena obra". Ambos convinieron en que la devolución de dicho préstamo fuera mediante el trabajo del oficial, "en casa del susodicho [Salas] en lo tocante a mi oficio de ensamblador". Alcalde ganaría 12 reales por jornal "sin dexar de trabajar todos los días de trabaxo sin que me aya de dar de comer ni otra cosa". Empezaría a laborar el 25 de febrero siguiente, y en adelante debía de cumplir 33 jornadas de trabajo, aproximadamente, para cancelar la deuda. Ahora bien, si en caso Lucas Alcalde incumpliera con su parte, Salas podía demandarle ante la justicia, e incluso privarle de su libertad. Obligación, Lima, 1642, protocolo notarial 1821, folio 21-21v., AGN, Lima. Citado en: Rafael Ramos Sosa, "Retablos y esculturas,” 399.

21. Concierto y apartamiento, Lima, 1642, protocolo notarial 1862, folios 361v.-362v., AGN, Lima. Citado en: Carlos Alfonso Villanueva, "Asencio de Salas: pecador público," Revista del Archivo General de la Nación, no. 15 (1997): 147. 
Un caso que llama la atención en ese sentido, es la deuda de 400 pesos(8) que mantenía Pedro de Noguera con Francisco Lobo, natural de Zafra (España)22, por los días de trabajo que cumplió este "como oficial descultor", en casa de Noguera. Lobo, por su parte, tenía a la vez una cuenta pendiente, por la misma cantidad, en favor de su suegro, el piloto del mar del Sur Fernando Álvarez de la Biesca. Lobo resolvió zanjar sus deudas. Comprometió a Noguera a que pague directamente a Álvarez de la Biesca la cantidad que le adeudaba, mediante una escritura de obligación fechada el día 30 de enero de 1631. A Noguera le tomó casi un año cancelar dicho pago, como consta en la anotación marginal en el mismo documento, fechada el día 14 de noviembre de ese año. Aquel día el piloto Álvarez daba por "rota y chancelada esta escritura, atento a resibido de Pedro de Noguera los quatrocientos pesos de a ocho [reales]"23.

No era la primera vez que Noguera mantenía cuentas pendientes con oficiales que habían trabajado en su tienda. Años atrás había ocurrido lo mismo con el oficial tallista Domingo Pérez de Lizarde, según la información contenida en una escritura firmada con el maestro catalán, el día 16 de febrero de 1626. En concreto, Lizarde reclamaba un pago de 136 pesos (8), producto del tiempo que trabajó con Noguera en la sillería de San Agustín. De hecho, estaba siguiéndole un pleito por esa causa; sin embargo, el maestro aducía que en realidad era Lizarde quien no había cumplido con su parte, al no completar el encargo que se le pidió, el cual consistió en "hacer cantidad de marioletas mascarones y entrecloses". Sea como fuere, para evitar seguir prolongando más el litigio, pues estaba pendiente una corroboración de lo que le faltaba por hacer a Lizarde, ambos convinieron en que Noguera le pagaría 40 pesos (8) al oficial, "por todo lo que pretende", y que se los entregaría en los dos meses siguientes ${ }^{24}$.

Llaman la atención los casos de los oficiales aquí comentados porque cuando estos trabajaban como tales, se sabe que ya tenían una suficiente experiencia en el oficio de la talla a tal punto que ya venían algunos de ellos ejerciendo de manera independiente. Por ejemplo, antes de figurar como oficial ensamblador, Hernando de Josephe se intitulaba maestro carpintero el día 16 de junio de 1623, cuando contrató hacer una cuja, 0 cama, en madera de cedro, para Domingo de Pintasa, por 86 pesos $(8)^{25}$. Luego se inclinaría por el oficio de ensamblaje pues, como se ha visto, entró a laborar en el taller de

\footnotetext{
22. Testamento de Francisco Lobo, Lima, 1668, testamento del siglo XVII, legajo 74, expediente 28, folio 404-404v., AAL, Lima.

23. Obligación, Lima, 1631, protocolo notarial 1814, folio 47-47v., AGN, Lima. Citado en: San Cristóbal, La Catedral de Lima, 302.

24. Concierto y Obligación, Lima, 1626, protocolo notarial 78, folio 287-287v., AGN, Lima. Citado en: San Cristóbal, 305.

25. Concierto, Lima, 1623, protocolo notarial 220, folios 280v.- 281, AGN, Lima. Citado en: Emilio Harth-Terré y Alberto Márquez Abanto, "El artesano negro en la arquitectura virreinal limeña," Revista del Archivo Nacional del Perú 25, no. 2 (1961): 14.
} 
Pedro de Noguera como oficial ensamblador, a inicios de 1626. Poco después, ya concertaba como maestro escultor y ensamblador a comienzos de la siguiente década ${ }^{26}$. Pero parece que no le fue bien pues, como se sabe, nuevamente estuvo, como oficial ensamblador, al servicio de Pedro de Noguera con quien luego se enzarzó en un pleito judicial por abandono de trabajo y serle deudor.

El caso del extremeño Francisco Lobo fue diferente porque, según las primeras noticias que se han podido conocer de él en la ciudad de Lima, cuando trabajaba como oficial escultor en la tienda de Noguera, ya firmaba como maestro en dicho oficio en algunos otros documentos, alrededor del año de 1630. Incluso, parece ser que su trabajo le reportaba cierta estabilidad económica pues estaba por desposarse con Juana Álvarez de Bribiescas [sic], natural del puerto del Callao ${ }^{27}$. Puede sugerir la estima que por entonces se tenía de él como escultor, el hecho de haber sido considerado por el excelente escultor Pedro de Noguera para que trabaje como oficial tallista en su casa. En aquellos días Noguera estaba ocupado en las obras de la sillería de coro de la catedral de Lima. La labor prestada por Lobo al maestro catalán bien pudo obedecer a la ejecución de la parte escultórica que debía ostentar dicha sillería.

Pero Lobo no solo tenía la capacidad de tallar en madera, sino también en piedra pues, al poco tiempo de cumplir con dichas labores lignarias en la tienda de Noguera, participó en las importantes obras de cantería de la portada principal de la catedral de Lima, dirigidas por el maestro mayor de fábricas, el escultor y alarife Juan Martínez de Arrona. En aquella oportunidad, Lobo labró una figura de un ángel destinada a una de las enjutas del arco, según recibo de pago firmado el día 6 de septiembre de $1631^{28}$.

26. El día 3 de julio de 1631, se obligó hacer un tabernáculo para la iglesia de San Sebastián (Concierto, Lima, 1631, protocolo notarial 864 , folios 493v.-496, AGN, Lima), aunque luego terminaría transfiriendo el encargo al ensamblador Tomás de Aguilar, el día 14 de abril del año siguiente (Obligación, Lima, 1632, protocolo notarial 865, folios 378-381v., AGN, Lima); y el día 3 de enero de 1633, un facistol con linterna para el convento dominico de recolección de la Magdalena. Por ese trabajo cobró 650 pesos (8), como reconoció en una anotación marginal del concierto, fechada el 28 de julio de ese año (Concierto y obligación, Lima, 1633, protocolo notarial 334, f. 6-6V., AGN, Lima). Las referencias documentales se citaron en: San Cristóbal, La Catedral de Lima, 303.

27. Gestoso ofrece una noticia somera acerca de un entallador apellidado Lobo que trabajaba en la catedral de Sevilla, en el año de 1620. José Gestoso y Pérez, Ensayo de un diccionario de los artífices que florecieron en Sevilla desde el siglo XIII al XVIII inclusive (Sevilla: La Andalucía Moderna, 1899), 1: 189. Por lo pronto, la primera noticia inédita hasta ahora de Francisco Lobo en la Ciudad de los Reyes data del 17 de marzo de 1629, fecha en la que Garci Báez Enríquez vende a Lobo un esclavo de 18 años, bozal de casta Biafra, por 600 pesos (8): Venta, Lima, 1629, protocolo 262, folios 158-159v., AGN, Lima. Por otra parte, también es posible que su matrimonio con Juana Álvarez, mediante la dote proporcionada por el padre de la novia, le aportara la solvencia necesaria para instalar un taller y contratar obras: Quiroz Chueca, Artesanos y manufactureros, 83. En el caso de Lobo, la dote que recibió de su suegro, Fernando Álvarez de la Biesca, entre el 16 de mayo de 1629 y el 31 de enero de 1631, consistió en ajuar y casas que sumaron el valor de 3025 pesos (8), a lo cual se sumaban las arras de 1000 pesos (8) donadas por el novio: Dote, Lima, 1629, protocolo 1813, folios 82-83v., AGN, Lima; Entero de dote, Lima, 1631, protocolo notarial 1814, folio 105-105v., AGN, Lima.

28. San Cristóbal, La Catedral de Lima, 234-235. Actualmente, en las enjutas del arco de la portada principal de la catedral se conservan sendos ángeles hechos en piedra, uno de los cuales San Cristóbal considera de Francisco Lobo. Posteriormente, el escultor de Zafra 
Domingo Pérez de Lizarde inició su formación en el oficio de entallador y escultor en la tienda del maestro Martín Alonso de Mesa, conforme al concierto de aprendiz que ambos firmaron el día 18 de agosto de 1615. Lizarde declaró tener entre 22 y 25 años de edad. El concierto establecía que serían cuatro años de aprendizaje, en los cuales el maestro "le a de dar oficial de los dichos oficios"29. Años después, antes del problema con Noguera, se sabe que participó en la construcción de un retablo junto con otros artífices. La noticia proviene de un contrato que firmaron el maestro dorador y estofador Fabián Gerónimo y el capitán Hernando de Santa Cruz y Padilla, el día 24 de octubre de 1624. Gerónimo debía encargarse de dorar y estofar el mueble litúrgico que sería destinado a la capilla familiar del capitán, que patrocinó bajo la advocación de la santa ApoIonia en la catedral de Lima. El documento revela de manera significativa, en palabras de Fabián Gerónimo, los nombres de los artífices que habían colaborado en la fábrica del retablo, el cual pasaría luego al dorador que declaró así: "me obligo de dorar y estofar el retablo que el dicho capitán tiene hecho de mano de Pedro de la Cueva y Domingo Pérez y traza de Pedro de Noguera y escultura de Luis de Espíndola"30.

A pesar de que la participación de Domingo Pérez en la importante sillería de coro agustina no fue reconocida económicamente como él pretendía, pudo ascender al grado de maestro al poco tiempo. Así, en compañía de su colega, el escultor Rodrigo de Padilla, contrataron la hechura de un retablo dedicado a la advocación de Nuestra Señora de la Caridad de Yllescas, para el hospital del señor san Diego, el día 30 de agosto de 1628. Se obligaron a entregar el retablo, decorado con tablas de pintura al óleo, dorado y estofado, en los seis meses siguientes. Por ese trabajo cobrarían el valor de 920 pesos (8)

\footnotetext{
fue requerido, hasta en dos oportunidades más, en el desarrollo de la fábrica de la portada catedralicia, para labrar unas marioletas, capiteles de columnas, y un escudo de armas reales. San Cristóbal, 243 y 302; cfr. Rafael Ramos Sosa, "Nuevas Noticias del escultor Bernardo Pérez de Robles en Perú," Revista del Departamento de Historia del Arte 16 (2003): 458. El arquitecto Harth-Terré, refiere sin citar fuente documental, la existencia en Lima de un escultor y pintor trujillano también llamado Francisco Lobo, a quien lo documenta desde el siglo XVI, pero lo confunde luego con el escultor segedano, Emilio Harth-Terré, "Pinturas y pintores en Lima virreinal," Revista del Archivo Nacional del Perú 27, no. 1 y 2 (1963): 189.

29. Concierto de aprendiz, Lima, 1615, protocolo notarial 420, folios 920v.-921v., AGN, Lima.

30. Concierto y obligación, Lima, 1624, protocolo notarial 1851, folios 451-452v., AGN, Lima. Citado en: San Cristóbal, La Catedral de Lima, 299, 400. No se conoce las características que debió tener el retablo del capitán, sin embargo, debió de ser una obra de importancia por los destacados artífices que colaboraron y los encargos artísticos que lo ornarían. Entre ellas, una escultura de santa Apolonia, adquirida en Sevilla por un precio de 1000 pesos, en el taller del sobresaliente escultor de Alcalá Juan Martínez Montañés, en el año 1625. En la actualidad, en la capilla de santa Apolonia de la catedral de Lima, no se conserva el retablo, pero sí la escultura de la santa que, al parecer, es la misma que talló Montañés por encargo de Hernando de Santa Cruz, ver: Jorge Bernales Ballesteros, "La escultura en Lima, siglos XVI-XVIII," en Escultura en el Perú (Lima: Banco de Crédito del Perú, 1991), 65; Rafael Ramos Sosa, "La fama de Montañés y su escuela en Hispanoamérica," en Montañés, maestro de maestros, eds. Ignacio Cano Rivero, Ignacio Hermoso Romero, y María del Valme Muñoz Rubio (Sevilla: Junta de Andalucía, 2019), 53-55. Catálogo publicado en conjunto con una exhibición del mismo título, organizada y presentada en el Museo de Bellas Artes de Sevilla, 29 de noviembre de 2019-15 de marzo de 2020.
} 
que, a consideración de ambos, era un precio justo pues "como maestros que somos sabemos su valor"31.

Como se ha visto hasta el momento, el trabajo de los oficiales tallistas se subsumía a los requerimientos del taller; y los resultados del mismo, al juicio artístico de los maestros del oficio. Este celo profesional seguramente estaba en relación con el interés del maestro por mantener un taller diligente y competitivo, a tal punto que talleres del mismo gremio podían disputarse la adjudicación de una obra importante. Conocidos son los casos en que este tipo de situaciones acompañaron o precedieron las construcciones tanto de la sillería de coro de la iglesia de san Agustín como de la catedral ${ }^{32}$. Los ejemplos que se acaban de citar se presentan como casos extremos que involucraron directamente a maestros examinados; sin embargo, se tiene noticia de algunos otros hechos relacionados con algunos oficiales tallistas, los cuales deben ser entendidos no solo desde el punto de vista de la práctica artística, sino desde el punto de vista del gremio a la que ellos pertenecían, para una mayor comprensión del escenario artístico limeño.

\section{Restricciones gremiales}

Antes de comentar las noticias referidas, es necesario indicar algunos aspectos del gremio que reunió a los artesanos tallistas. Para empezar, los oficios de la escultura y la ensambladura quedaron agrupados dentro del gremio de los carpinteros, que debió de constituirse formalmente ante el Cabildo de Lima, en el último cuarto del siglo XVI ${ }^{33}$.

31. Concierto, Lima, 1628, protocolo notarial 1950, folios 111-113v., AGN, Lima. Citado en: San Cristóbal, La Catedral de Lima, 305. No se le conoce algún otro concierto de obra en su haber, por el momento. Pero parece que no le fue mal pues el 27 de agosto de 1632 arrendó unas casas principales por un año, con tienda y trastienda, de propiedad de doña Polonia Fajardo, a 300 pesos (8) (Arrendamiento, Lima, 1632, protocolo notarial 1643, folio 424-424v., AGN, Lima). Posiblemente también instaló ahí su taller, como era lo usual, a juzgar por el espacio y coste de alquiler del local, ver: Harth-Terré y Márquez Abanto, "Perspectiva social," 400-404. Alrededor de esos años, otros escultores rentaban casas a precios similares como por ejemplo la casa de propiedad de don Sancho Bravo de Lagunas, que alquiló a 320 pesos (8) por año, al escultor sevillano Gaspar de la Cueva, el 12 de mayo de 1627 (Arrendamiento, Lima, 1627, protocolo notarial 4, folios 318-319v., AGN, Lima) o la "casa de vivienda" de propiedad de doña Leonor Menacho que alquiló a 300 pesos (8) por año, al escultor extremeño Pedro Muñoz, el 30 de septiembre de 1628 (Arrendamiento, Lima, 1628, protocolo notarial 1920, folios 606v.-607, AGN, Lima).

32. Antonio San Cristóbal, "Algunas sillerías corales limeñas," Revista del Archivo General de la Nación, no. 6 (1984): 72-76; San Cristóbal, La Catedral de Lima, 283-347; Rafael Ramos Sosa, "El escultor-imaginero Gaspar de la Cueva en Lima (1620-1628)," en La consolidación del Barroco en la escultura andaluza e Hispanoamérica, coord. Lázaro Gila Medina (Granada: Universidad de Granada, 2013), 429-430; Enrique Marco Dorta, Fuentes para la historia del arte hispanoamericano. Estudios y documentos (Sevilla: Consejo Superior de Investigaciones Científicas, 1960) 2: 88-94, 263-296.

33. Ante la insistencia del Cabildo los carpinteros decidieron agremiarse, de manera efectiva, a partir del año 1575, ver: Lima. Consejo Provincial, Libros de Cabildos de Lima (Lima: Consejo Provincial), 8: 27-28, 101-103; 9: 20-21. Aunque no se puede precisar si desde esa época los escultores y ensambladores participaron como miembros del gremio de carpinteros, se sabe que en la primera mitad del 
Aunque no se han localizado aún las ordenanzas que regían dicha corporación, existen suficientes indicios para afirmar que estas existieron efectivamente. Las referencias que se hacen de ellas en los cabildos concernientes a las elecciones de sus autoridades-alcalde, veedores y examinadores-, así lo evidencian ${ }^{34}$. Sin embargo, no es posible conjeturar el tenor de cada una de sus disposiciones. En su lugar, puede citarse alguna documentación indirecta de la época, por la cual pueden intuirse algunas de ellas que se consideran relevantes para este trabajo.

En primer lugar, como ya se ha mencionado, el aprendizaje era el primer paso para iniciarse en la formación de un oficio determinado. Existen varios asientos de aprendiz que se han recopilado de los protocolos notariales del Archivo General de la Nación del Perú. En algunos de estos documentos se alude al interés del alumno por convertirse en "oficial perfecto", o trabajar como oficial ${ }^{35}$. Por el contrario, en los asientos con oficiales, no hay alguna alusión por parte de estos a querer llegar a ser maestros. Sin embargo, se deduce que el oficial debía examinarse y así ser promovido, porque el Cabildo despachaba finalmente las cartas de examen, que eran necesarias para ejercer legítimamente el oficio ${ }^{36}$.

En segundo lugar, casi no existe información sobre el contenido de las mencionadas cartas de examen. Solo se saben de ellas por las referencias de los libros de Cabildos de Lima. Dichas cartas debían contener datos del artífice y la especialidad en la que el maestro se desempeñaría, y no otra, de modo que no incurra en una falta ${ }^{37}$. Como se

siglo siguiente dicho gremio eligió hasta en tres ocasiones al escultor Pedro de Noguera como uno de sus veedores y examinadores. En la primera de ellas, el Cabildo desestimó dichas elecciones por considerarlas ilegítimas, y en su lugar nombró al carpintero BartoIomé Calderón, (16/10/1623). En las dos siguientes, pudo jurar al cargo ante el Cabildo, sin ningún problema (06/06/1625, 21/08/1626).

34. Lima. Consejo Provincial, Libros de Cabildos de Lima, 15: 896; 17: 226, 643; 19: 130, 702-703; 20: 128-129, 369, 569-570; 22: 284-285; 23: 114-115, 116-117, 236, 468.

35. Asiento de aprendiz, Lima, 1615, protocolo notarial 420, folio 922, AGN, Lima; Asiento, Lima, 1610, protocolo notarial 267, folio 2-2v., AGN, Lima. Citado en: San Cristóbal, "El ensamblador Tomás de Aguilar," 180.

36. Hasta el año 1639, no consta alguna carta de examen despachada a escultores o ensambladores, en las actas del Cabildo de Lima. Hasta donde se sabe, el único caso publicado sobre el tema lo dio a conocer el profesor Rafael Ramos Sosa, "La pervivencia del manierismo en Lima. El motivo ornamental de la sillería del monasterio de santa Catalina(1662)," en Actas IX Congreso español de Historia del Arte (León 29 de septiembre a 2 de octubre de 1992), coord. Comité Español de Historia del Arte (León: Universidad, Secretariado de Publicaciones, D.L., 1994), 447, nota 3. Se trata de la carta de examen que el Cabildo despachó al ensamblador y carpintero Asensio de Salas, el 18 de junio de 1640. Con respecto a los carpinteros, propiamente dichos, tampoco fueron muy aplicados al respecto, pues recién a partir del año 1609 empezaron a tramitar dicho documento ante el Cabildo. Parece ser que esto aconteció debido a que la cúpula gremial de los carpinteros decidió ejercer mayor control sobre sus pares, agremiados o no, exigiéndoles las cartas de examen correspondientes: Antonio San Cristóbal, "El carpintero mudéjar Antonio Velásquez," Revista del Archivo Nacional del Perú, no. 15 (1997): 162. Con esa medida adoptada podría pensarse que la real intención de las autoridades gremiales del oficio era cerrar el paso a la competencia.

37. Francisco Quiroz, Gremios, razas y libertad de industria (Lima: Facultad de Ciencias Sociales Universidad Nacional Mayor de San Marcos, 1995), 33-39. 
ha dicho, el gremio de los carpinteros agrupaba a otros oficios, cuyas especialidades debían requerir de diferente preparación en el trabajo con la madera ${ }^{38}$. En conformidad con este punto se han encontrado algunos asientos de aprendizaje firmados entre carpinteros en formación, o plenamente formados, con maestros de diferente oficio, los cuales emprendían de ese modo otra especialización afín ${ }^{39}$.

Y, en tercer lugar, según los datos recogidos de los libros de Cabildos de Lima, desde el principio de su constitución gremial, los carpinteros prohibieron el ejercicio del oficio a los artífices tallistas no examinados, y a los grupos de origen africano, salvo expresa licencia del Cabildo ${ }^{40}$. Es decir, estos últimos no tenían la posibilidad de rendir un examen de suficiencia para ser promovidos a maestros. Esta disposición del gremio, parece que no solo persistió, sino que se extendió a los mestizos a comienzos del siglo siguiente ${ }^{41}$.

Estos puntos enumerados están a tono con las ordenanzas que regían en general a los gremios de la ciudad ${ }^{42}$. Pero parece que ellos no tuvieron eficacia normativa. Por ejemplo,

38. Se deduce que el gremio de carpinteros aglutinaba también a los torneros y guitarreros, por los hechos siguientes. Las autoridades del citado gremio presentaron su declaración en la que constaba haber examinado al tornero Gregorio de Mesa en dicho oficio. En virtud de ello, el Cabildo mandó despachar la correspondiente carta de examen al interesado, el día 3 de octubre de 1631: Lima. Consejo Provincial, Libros de Cabildos de Lima, 22: 78. Más interesante es el caso del guitarrero Gaspar de Urbina, pues sin poseer carta de examen él ya venía ejerciendo su oficio en taller propio y públicamente, por más de 20 años. Esto debido a que no había maestros en la ciudad que pudieran examinarle, según argumentó. Ciertamente, no era el único en su oficio, pues sostenía además que era el mejor en su campo. Por estas razones, solicitaba al Cabildo le despachen carta de examen y lo nombren examinador para el resto de oficiales, lo cual revela sus reales motivaciones. El Cabildo le concedió licencia para el debido funcionamiento de su tienda pública, como si fuera maestro examinado, y lo nombró no solo examinador sino también veedor, para que "pueda visitar y visite las obras que hicieren y tuvieren en sus tiendas [ sus colegas del oficio]", según actas del Cabildo del día 17 de diciembre de 1621: Lima. Consejo Provincial, Libros de Cabildos de Lima, 19: 168-169. En el periodo de estudio, se sabe que una primera generación de escultores ejercía como ensambladores indistintamente. Sin embargo, a finales de la segunda década del siglo XVII, tomaría la posta otra generación de tallistas que se especializarían o bien en ensambladura o bien en escultura, ver: Antonio San Cristóbal, "El ensamblador arequipeño Juan Gutiérrez Coronado," Historia, no. 3 (1988): 260; Antonio San Cristóbal, "El ensamblador Mateo de Tovar y la evolución de los retablos en Lima," Boletín del Instituto Riva Agüero, no. 23 (1996): 242-243.

39. Además del caso de Hernando de Joseph, ya tratado, puede mencionarse el del joven carpintero llamado Juan Carrero, natural de Jerez de la Frontera. Carrero asentó con el escultor y entallador sevillano Martín de Oviedo, para que este le enseñara "el oficio de entallador y arquitectura". El convenio se firmó el día 4 de febrero de 1604, y tendría una duración de un año. El asiento tenía visos de contrato a jornal pues Carrero debía asistir a Oviedo "en todo lo que me mandare del dicho mi oficio de carpintero", por lo cual cobraría 120 pesos (9) pagados en tercias partes, cada cuatro meses; el concierto agregaba un servicio adicional a favor de Carrero: Oviedo debía asumir el costo del lavado de su ropa cada semana. Concierto, Lima, 1604, protocolo notarial 306, folios 509v.-510v., AGN, Lima. Citado en: José de Mesa y Teresa Gisbert, Escultura Virreinal en Bolivia (La Paz: Academia Nacional de Ciencias de Bolivia, 1972), 100.

40. Lima. Consejo Provincial, Libros de Cabildos de Lima, 8: 102.

41. Según el laborioso investigador San Cristóbal, en el Cabildo de la Cofradía y Hermandad de San José de los carpinteros, llevada a cabo el día 18 de octubre de 1609, se tomaron algunos acuerdos tocantes a su institución religiosa y a su gremio. Uno de estos acuerdos, de índole gremial, fue que "ningún mestizo mulato y negro pueda ser examinado de nuevo y tomar obras pena de veinte pesos para la Cofradía y la Cámara de Su Majestad". No se ha podido compulsar la información brindada por el autor pues la referencia documental que citó es una errata. San Cristóbal, "El carpintero mudéjar," 162. El artículo apareció de nuevo en: Antonio San Cristóbal, Arquitectura virreinal de Lima en la primera mitad del siglo XVII (Lima: Fondo Editorial FAUA, 2003), 1: 112. Pero aquí también figura la misma errata.

42. Quiroz logró acopiar distintas ordenanzas gremiales que rigieron las actividades artesanales de Lima, las cuales presentó y estudió su contenido. Es llamativo que el autor destaque en primer término el carácter restrictivo de las ordenanzas, en varios niveles, 
con respecto a la especialización de los oficios, existe un caso que ha llamado la atención, y que se trae a colación con todo detalle por la elocuencia de los hechos. Se trata de la concesión de una obra de ensambladura y escultura que enfrentó al prestigioso escultor sevillano Martín Alonso de Mesa y al maestro carpintero Pedro Alfonso de Avilés. El caso reviste de interés porque Avilés, hasta donde se sabe, fue solo maestro carpintero y no ensamblador ${ }^{43}$. De hecho, Mesa lo tuvo por oficial en su taller. La obra en cuestión consistía en la hechura de un retablo con sus esculturas el cual además debía ser entregado dorado y estofado, e instalado en el altar mayor de la iglesia del monasterio de la Encarnación. Las monjas de dicho monasterio ya habían convenido con Martín Alonso de Mesa, que había ofrecido hacerlo por 11,000 pesos (8). La pretensión de Avilés, al parecer, se dio justo antes de que se concretara dicho acuerdo ante el notario.

El día 31 de julio de 1612, el maestro carpintero Avilés, que para esta oportunidad se intituló ensamblador, presentó una petición junto con el escultor Domingo Márquez ante el arzobispo de Lima, Bartolomé Lobo Guerrero, para que se les admitiera su contrapropuesta. Ellos ofrecieron hacer el citado trabajo en menor precio, 9,000 pesos (8); además, no cobrarían dinero alguno hasta haber hecho toda la obra, y con la condición de que dos escultores declararen antes la conformidad de lo realizado con la traza propuesta por Mesa. Incluso Avilés solicitaba al arzobispo que vea una traza o diseño de retablo que él tenía comenzada y que sería "de más aumento para dicho convento". La solicitud de Avilés llamó la atención del prelado que el mismo día mandó traer las dos trazas, tanto la de Avilés como la de Mesa, "para que vistos, su Santa llustrísima provea lo que más convenga". La intención de Avilés y compañía se encontró con una rápida y convincente respuesta por parte de Martín Alonso de Mesa con el fin de hacerse definitivamente con la empresa.

En primer lugar, Mesa tuvo a su favor la apreciación que el reputado artífice Juan Martínez de Arrona y el platero Diego de la Torre hicieron de la traza presentada por el

\footnotetext{
con respecto al ejercicio de las actividades artesanales como el de la competencia profesional del artesano, el origen étnico de los mismos, el económico, entre otros: Francisco Quiroz Chueca y Gerardo Quiroz Ch., Las ordenanzas de gremios de Lima (s. XVI- XVIII) (Lima: Artes diseño gráfico, 1986), XXII-XXV.

43. A solicitud de Pedro de Avilés, el Cabildo le despachó, meses antes que se produzca el enfrentamiento con Mesa, una carta de examen del oficio de carpintero, el día 19 de noviembre de 1611. Como las autoridades del Cabildo explicaron, la carta de examen habilitaba al maestro para "que pueda tener tienda pública del dicho oficio con oficiales y aprendices sin incurrir en pena alguna y hacer en ella las piezas en que fue examinado y no más": Lima. Consejo Provincial, Libros de Cabildos de Lima, 16: 517-518. En realidad, Avilés había regularizado su situación pues ya tenía una tienda instalada donde ejercía el oficio, al menos, desde el año anterior. Así, el día 07 de enero de 1610 firmó una escritura de asiento con Tomás de Aguilar, a quien lo recibió en su casa por aprendiz para enseñarle durante cuatro años el oficio de carpintero "sin le yncubrir cosa alguna". Al final de dicho tiempo le proporcionaría entre otras cosas, un aparejo de herramientas para que pueda "trabajar como oficial en qualquiera tienda": ver cita 35, segundo documento.
} 
escultor. Incluso, el primero declaró que no lo haría por menos cantidad de la que solicitaba Mesa. Aun así, este rebajó en 1,000 pesos (8) su propuesta inicial para hacerlo, y aducía que como tenía dos hijas novicias en el monasterio, y otra niña más por entrar, las monjas de la Encarnación podían usar los 10,000 pesos (8) que debía cobrar Mesa por el retablo, para saldar los elevados gastos que se generaren por la dote, ajuar y propinas de sus hijas que iban a profesar como religiosas en el cenobio.

Otro argumento de Mesa para refutar la oferta del contrario, fue sostener que el maestro carpintero no tenía experiencia como ensamblador, "ni en su vida aver fecho semejantes obras". El escultor sabía bien lo que decía puesto que fue "oficial mio [y] no es suficiente para hacer la dicha obra con la perfección y arte que requiere". En realidad, lo tenía por aprendiz "como es notorio" y advirtió que no era oficial examinado. Y si en caso lo fuere, continuó diciendo, "no es hombre quantioso ni persona de satisfación ni crédito para hallar las fianzas que se requieren para el concierto de esta obra". Para rematar el asunto, Mesa arguyó la conveniencia de que sea él quien se haga cargo de la obra "porque siendo de mi mano y arte la dicha obra tendrá mucho más valor y perfección porque como se sabe en este reyno no hay persona en él que me haga ventaja en la dicha arte descultura".

Las razones que adujo Mesa debieron parecerle suficientes al arzobispo porque casi de inmediato, al día siguiente, dio licencia al mayordomo del monasterio de la Encarnación para que encarguen el retablo a Martín Alonso de Mesa, y se celebre el concierto de obra correspondiente. Sorprende que el maestro escultor y las monjas de la Encarnación preparasen el extenso concierto que constó de doce folios con las nuevas condiciones y lo firmasen ante un notario ese mismo día, el 1 de agosto de aquel año ${ }^{44}$.

Dos cosas para enfatizar. Primero: siendo Avilés carpintero, pujó una obra de ensambladura, que no le correspondería llevar a cabo, según las restricciones corporativas del gremio. Y segundo: una vez atendida la propuesta de Avilés, Mesa se vio forzado a hacer una contrapropuesta, que consistió en la rebaja del coste de la obra, con cómodas formas de pago, para luego señalar puntualmente, por supuesto, la incompetencia de su rival y el prestigio artístico que tenía él en la ciudad.

Hasta el momento, solo se conoce un concierto de obra firmado por Pedro de Avilés, y es como carpintero ${ }^{45}$. Más bien destaca por haber sido elegido veedor, por los maestros

44. Sin título, Lima, 1612, protocolo notarial 51, folios 1101-1119, AGN, Lima. Citado en: San Cristóbal, La Catedral de Lima, 286.

45. El día 31 de mayo de 1613, se comprometió hacer unos trabajos de carpintería en las casas de Diego de Mayuelo: San Cristóbal, "El ensamblador Tomás de Aguilar," 181. 
de su oficio, cargo que juramentó ante el Cabildo, el día 3 de diciembre de 1612; es decir, al poco tiempo de su frustrado intento por ejecutar el retablo monástico. Dicho cargo le facultaba para vigilar el cumplimiento de las ordenanzas por sus colegas, agremiados o no, y detectar a los infractores para su posterior sanción ${ }^{46}$.

Con respecto a otro de los puntos señalados anteriormente, concerniente a la prohibición del ejercicio del oficio a los artesanos tallistas de origen africano e indígena, tampoco se cumplió estrictamente pues, además de los casos citados de Hernando de Joseph y Pablo Alonso, mulato y moreno libres, pueden referirse por ejemplo los del maestro ensamblador Mateo de Tovar, pardo libre, de extensa y destacada trayectoria en la ciudad de Lima, y de los maestros escultores Sebastián de Sande, mestizo, y Francisco Supo, indio ladino, de quienes aún no se conoce mucho, pero se sabe que contrataron obras para importantes recintos religiosos ${ }^{47}$. Tal vez el caso más llamativo y elocuente sea el del oficial escultor Juan Simón, mulato, que fue esclavo del mercader y clérigo Pedro González Refolio, en Lima.

Gracias a las investigaciones del profesor Rafael Ramos Sosa, se sabe ahora que Simón, antes de pertenecer al mercader, perteneció al prestigioso escultor español Juan Martínez Montañés, de quien habría aprendido el oficio en la ciudad de Sevilla. En 1604, pasó a propiedad de Refolio y al año siguiente se embarcó con él a la Ciudad de los Reyes, donde (como su nuevo amo) alquilaba su trabajo a destacados escultores y ensambladores del lugar, como a Juan Martínez de Arrona o a Martín Alonso de Mesa ${ }^{48}$. Debido a la formación que tuvo con el escultor de Alcalá, y al trabajo que hizo luego para importantes escultores en Lima, debió de tratarse de un escultor cualificado, aunque por su condición de esclavo nunca alcanzara el grado de maestro, por prohibición gremial ${ }^{49}$.

46. Quiroz, Gremios, 49-50.

47. Sobre Mateo de Tovar, ver: Antonio San Cristóbal, "El ensamblador Mateo de Tovar," 241-286. Sobre Sebastián de Sande, ver: Rafael Ramos Sosa, "La sillería coral de Santo Domingo de Lima," Archivo Español de Arte 68, no. 271 (1995): 311 y 313. En cuanto a Francisco Supo se sabe que, con licencia del corregidor de naturales, don Diego Mesia de Zúñiga, el día 26 de noviembre de 1631, concertó con Pedro de Mesa hacerle toda la obra de escultura para un retablo que Mesa debía hacer para la iglesia de Nuestra Señora de Monserrate, en Lima: Concierto, Lima, 1631, protocolo notarial 1854, folios 837v.-839, AGN, Lima. Citado en: San Cristóbal, La Catedral de Lima, 303. De Supo, pueden ofrecerse además estas noticias: el 1 de noviembre de 1628, había concertado hacer una imagen de san Lucas para los mayordomos de la cofradía de dicho santo, fundada en la Recoleta dominica de la Magdalena. Parece que la imagen la doraría Juan de Cáceres, pues al día siguiente se presentó como su fiador: Concierto, Lima, 1628, protocolo 776, folios 336-338v., AGN, Lima. Y el 25 de setiembre de 1649, se encargó de hacer una imagen de san Pedro Mártir de santo Domingo, para el Reino de Chile: Concierto de obra, Lima, 1649, protocolo notarial 30, folio 742-743, AGN, Lima.

48. Rafael Ramos Sosa, "El escultor Juan Simón: discípulo y esclavo de Montañés," en Migraciones y rutas del Barroco, ed. Norma Campos Vera (La Paz: Fundación Visión Cultural, 2014), 37-45.

49. Sin embargo, ya a finales del siglo XVI había un grupo numeroso de maestros morenos libres, ejerciendo los oficios de alarifes y carpinteros, Harth-Terré y Márquez Abanto, "El artesano negro," 11. De ahí que, a comienzos del siglo XVII, la prohibición del gremio de carpinteros para que no se examinen "de nuevo", ni tomen obras (ver cita 41), delaten la ineficacia de la norma. 
El 10 de julio de 1607, Refolio firmó un contrato con el escultor Arrona, por el cual Simón le asistiría en su casa durante un año, como oficial. Por su trabajo se le pagarían 3 pesos (8) cada día, más alimentación ${ }^{50}$. Se trató de un contrato a jornal, pero en lugar de que cobrare el oficial, lo haría en realidad su amo Refolio "al fin de cada semana". La cantidad de 3 pesos (8) es el jornal más elevado pagado a cualquier oficial del que se tiene registro hasta ahora ${ }^{51}$, lo cual es un indicativo de su capacidad como escultor. En el mismo contrato, Arrona reconocía dicha aptitud del oficial pues "... Io es [escultor] y de lo que sabe estoy enterado y satisfecho por aver trabajado en mi casa y compañía".

Años después, el día 3 de enero de 1619, Refolio concertó con Martín Alonso de Mesa para que Juan Simón le hiciera unas obras de escultura que tendrían como destino el retablo mayor de la iglesia del monasterio de la Concepción. El plazo del contrato fue fijado en un año, tiempo en que debía entregar la obra, conforme a una memoria firmada por ambas partes. El maestro escultor le proporcionaría el maderamen al oficial a partir del día 15, cuando empezaría a correr el tiempo pactado. Por la finalidad y tenor del documento, se trató de un contrato a destajo. Nuevamente llama la atención el pago

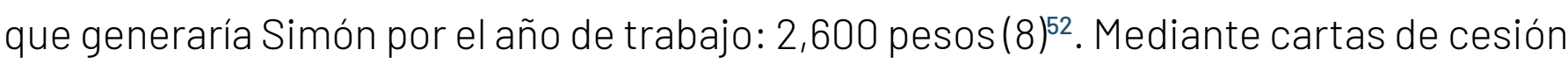
otorgadas por Mesa, Pedro González Refolio cobraría dicho dinero directamente de las monjas concepcionistas. Los plazos de pago serían los mismos en que el monasterio pagaría a Mesa por el retablo que estaba haciendo, en el que se colocarían "las figuras", de Juan Simón. Al parecer, Simón trabajaría en tienda aparte, probablemente en una instalada por su amo Refolio ${ }^{53}$.

Es importante recordar aquí que el origen étnico no tuvo ningún efecto a la hora de apreciar la capacidad del ejecutante, pero sí en el momento de establecer quiénes ejercerían libremente el oficio, en el periodo tratado. Simón fue uno de muchos casos

50. Concierto, Lima, 1607, protocolo notarial 1002, 2093v.-2094v., AGN, Lima. Citado en Rafael Ramos Sosa, "Juan Martínez de Arrona, escultor (c. 1562-1635)," en Euskal Herria y el Nuevo Mundo: la contribución de los vascos a la formación de las Américas. VI Congreso Internacional de Historia de América, coords. Ronaldo Escobedo Mansilla, Ana Zaballa Beascoechea, y Óscar Álvarez (Vitoria: Universidad del País Vasco, 1996), 570.

51. Además de los documentos que se ha consultado y citado en este trabajo, puede consultarse el estudio de Harth-Terré y Márquez Abanto, "Perspectiva social," 388-400.

52. El precio que había pagado Pedro González Refolio por Simón, fue de 300 pesos (8)(Ramos Sosa, "El escultor Juan Simón," 41). Ahora, el oficial mulato generaría para Refolio la exorbitante suma de 2600 pesos (8), en un año de trabajo; es decir, casi 8 veces más de lo que ganaba un oficial tallista, en promedio, por un año de jornales, 300 pesos (8). Aunque Mesa no completó el trabajo, se sabe que se cumplió con parte del trabajo escultórico. Antonio San Cristóbal, "Martín Alonso de Mesa y Juan García Salguero en el Retablo Mayor de la Concepción," Revista del Archivo General de la Nación, no. 17 (1998): 104, 106.

53. Ramos Sosa, "El escultor Juan Simón," 42. 
de oficiales esclavos, instruidos en un oficio, que asistieron en importantes talleres de la ciudad, algunos de los cuales, sin embargo, lograron su manumisión ${ }^{54}$.

\section{Consideraciones finales}

En general, los esfuerzos de cada cúpula gremial en Lima por controlar la producción de los talleres, conllevaron a la creación de medidas restrictivas para el ejercicio de los oficios ${ }^{55}$. Estas medidas que debían supuestamente salvaguardar la "calidad" del producto partieron desde el punto de vista de una clase minoritaria. En el caso del gremio de los carpinteros, el cual agrupaba a los artesanos de la madera, la situación no fue diferente. Como se ha mencionado, se dictaron disposiciones que prohibían el libre ejercicio del oficio a oficiales no examinados, pero también a negros y a mestizos, en una actitud expresamente discriminatoria. Sin embargo, en la práctica estas líneas divisorias eran fácilmente traspasadas incluso por los mismos maestros agremiados, que comprobaron la ineficacia de las normas.

El maestro carpintero Pedro de Avilés no podía participar de obras que no fueran de su especialidad, sin embargo, pujó una obra de retablo sin ninguna restricción gremial que le haya obstaculizado, más allá de los reclamos justos (pero insuficientes) de Martín Alonso de Mesa para adjudicarse el trabajo. Finalmente, Mesa se impuso a Avilés, pero posteriormente subcontrató a otro carpintero para que acabase el retablo en cuestión ${ }^{56}$. Este mismo escultor, en otra ocasión, integró a su muy activo taller el trabajo del oficial escultor mulato Juan Simón, cuya valía se deduce de los elevados costos de su servicio, con el cual lo alquilaba su amo.

En la práctica, estas restricciones arbitrarias del gremio fueron usados a conveniencia por los maestros. Cuando se trataba de contrarrestar la competencia eran estrictos con el

54. Harth-Terré y Márquez Abanto, "El artesano negro," 3-73. Es significativo el caso del oficial carpintero Ventura Tiburu. El día 16 de mayo de 1641, doña Gerónima del Peso le concedió a su esclavo mulato Tiburu una libertad condicionada al pago de 300 pesos (8), que debía efectuar al oficial carpintero Juan de Castañeda. Tiburu debía pagar con su trabajo su libertad. El tiempo que debía estar al servicio de Castañeda se estableció en 6 años, luego de lo cual conseguiría la manumisión. Sin embargo, a los dos años de dicho acuerdo, por voluntad testamentaria de Andrés Coronado, y mediante su albacea, Tiburu pudo pagar los 300 pesos (8), antes de tiempo. Castañeda accedió a dicho trato "por averle pedido personas de todo respeto que le haga suelto del dicho tiempo que le falta por cumplir": Sin título, Lima, 1641, protocolo notarial 1278, ff. 336v.-337v., AGN, Lima. Citado en: Harth-Terré y Márquez Abanto, "Perspectiva social," 445.

55. Quiroz Chueca y Quiroz Ch, Las ordenanzas, XXIII.

56. Se trató del carpintero Juan Gutiérrez Coronado que luego incursionaría en la ensambladura. San Cristóbal, “El ensamblador arequipeño," 258. 
Fig. 1. Juan Simón (atribuido por Rafael Ramos Sosa), La Anunciación, c. 1620. Talla en madera policromada

$160 \times 135 \mathrm{~cm}$. Museo del Palacio Arzobispal de Lima. (Fotografía de Daniel Giannoni).

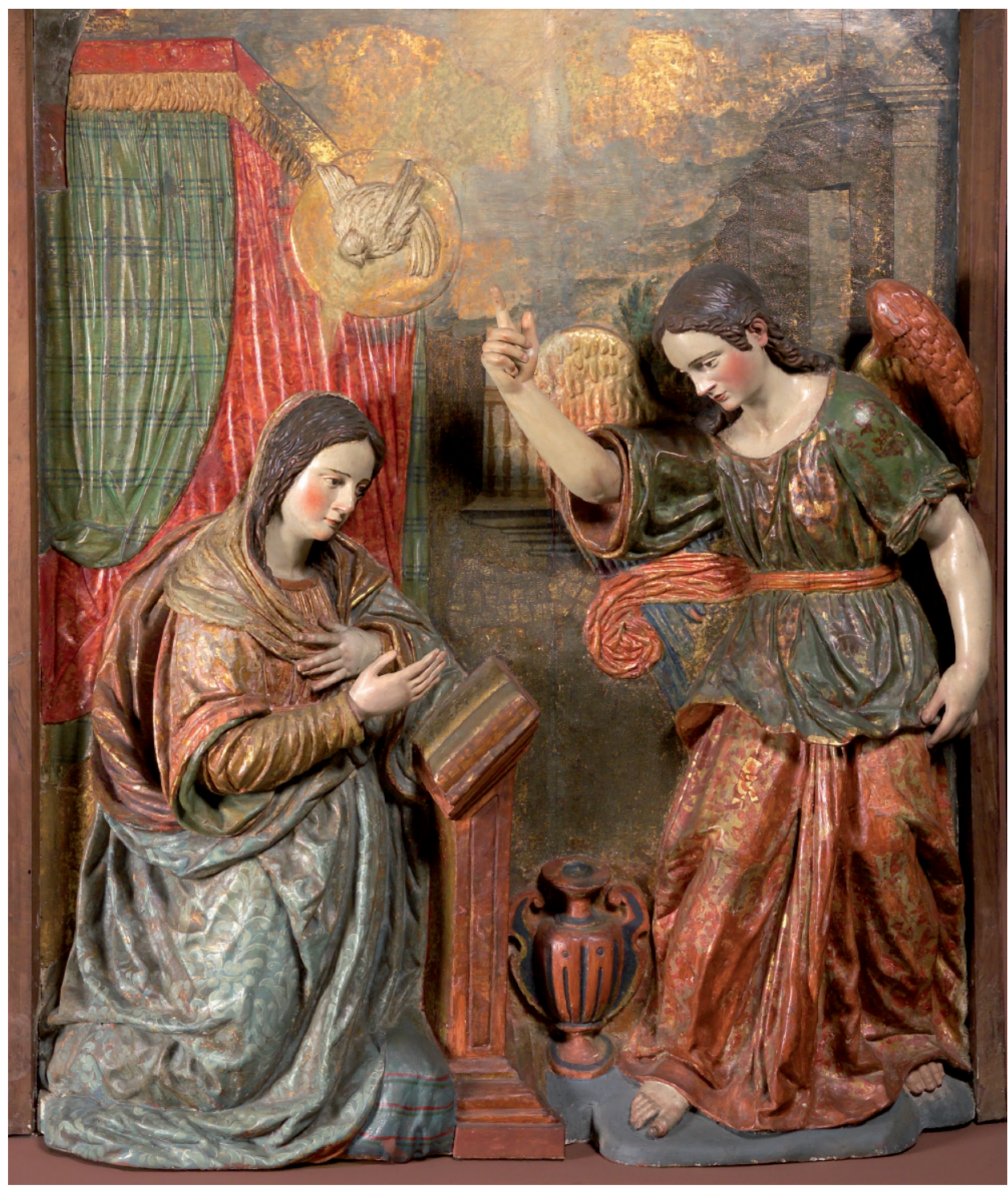

cumplimiento de sus reglamentos, sobre todo si tenía que ver con los sectores menos favorecidos ${ }^{57}$. Pero cuando se trataba de aprovecharse del trabajo de los oficiales, no distinguían ni oficios ni etnias. Esto obedecía ciertamente a la demanda artística que se imponía sobre dichas restricciones. En este escenario, había lugar para personalidades como la de Avilés, que, con escasa preparación o resultados artísticos desfasados, podía disputar obras que no le competían, lo cual, al parecer, no era exclusivo de este grupo privilegiado ${ }^{58}$.

57. Ver el caso del guitarrero Gaspar de Urbina, en cita 38. El día 27 de marzo de 1634, el Cabildo desestimó la solicitud del cirujano Bartolomé de Ortega que pretendió mandar a examinar a su esclavo en el oficio de tornero, para tener tienda pública. Las autoridades tuvieron en cuenta el pronunciamiento en contra de los veedores del gremio de los carpinteros y lo dispuesto por las ordenanzas, entre otras consideraciones, para declarar "no aver lugar de mandar examinar el dicho negro en consideración de serlo y esclavo que como tal le está prohibido por derecho el huso de los oficios públicos y aver en comprobación la hordenanza presentada en los dichos autos": Lima. Consejo Provincial, Libros de Cabildos de Lima, 23: 68.

58. En el campo de la pintura, Siracusano da cuenta del caso del clérigo Diego Calderón, que sin ser pintor tenía tienda, de dicho oficio, donde oficiales contratados copiaban pinturas para su venta. Gabriela Siracusano, "Para copiar las 'buenas pinturas'. Problemas gremiales en un estudio de caso de mediados del siglo XVII en Lima," en Manierismo y transición al Barroco: memoria del III Encuentro Internacional sobre Barroco, ed. Norma Campos Vera (La Paz: Unión Latina, 2005), 131-139. 


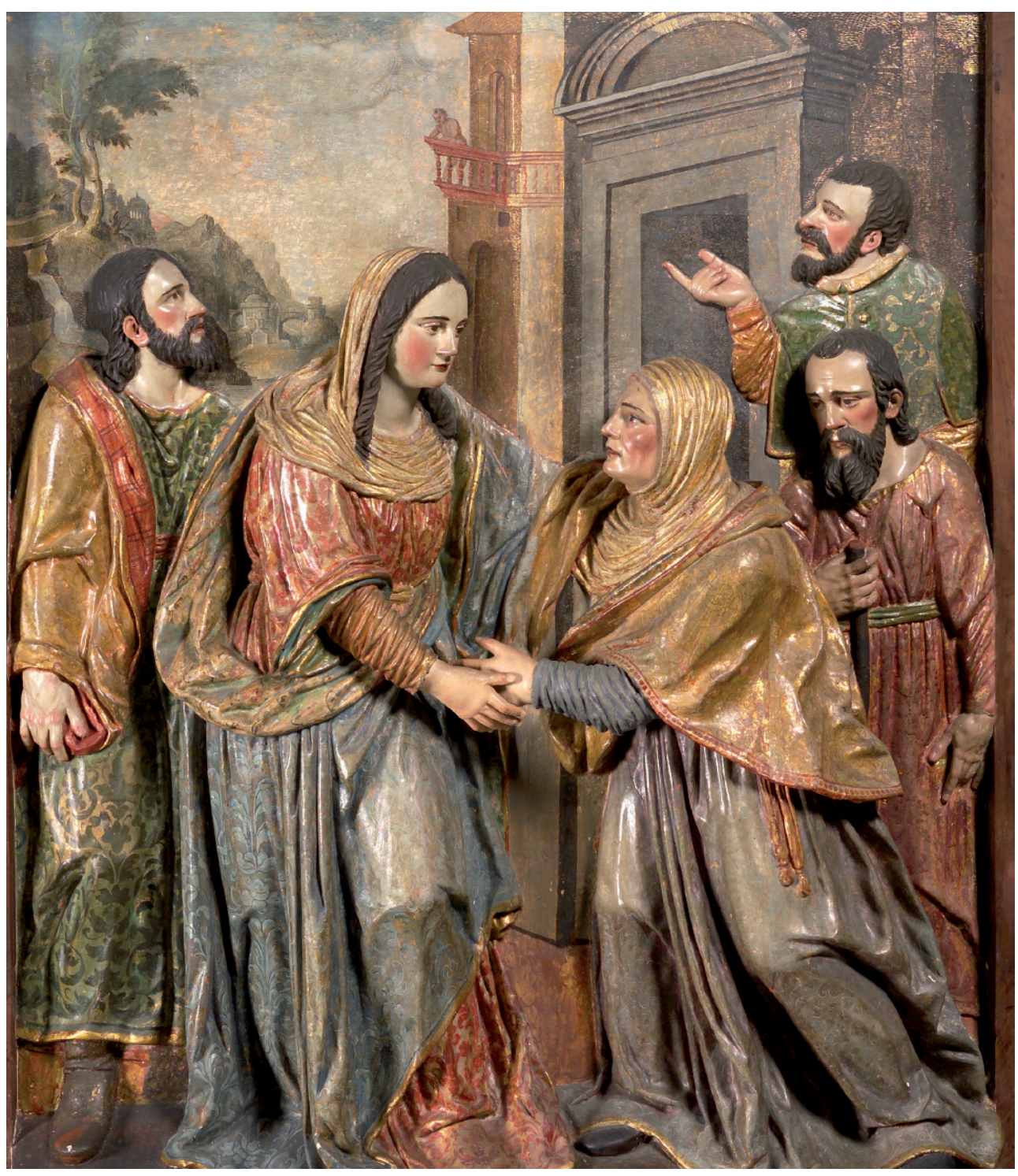

Fig. 2. Juan Simón (atribuido por Rafael Ramos Sosa), La Visitación, c. 1620. Talla en madera policromada, $160 \times 135 \mathrm{~cm}$. Museo del Palacio Arzobispal de Lima. (Fotografía de Daniel Giannoni).

Pero también había lugar para personalidades como la de Simón, que, sin llegar al grado de maestro y trabajar a la sombra de su amo, llamó la atención su trabajo por ser portador de un concepto artístico que se imponía poco a poco en la Ciudad de los Reyes.

Estas figuras secundarias, como Avilés o Simón, independientemente del cumplimiento o no de las disposiciones restrictivas de su gremio, fueron absorbidas tanto por la demanda artística imperante, como por los protagonismos de las figuras principales cuyos trabajos los distinguieron en el arte de la ensambladura y escultura limeños. Tanto la retablística como la escultura desarrollaron componentes y recursos plásticos propios a partir del segundo tercio del siglo XVIII9. Prácticamente han desaparecido los

59. Antonio San Cristóbal, "Las escuelas de los retablos virreinales," Histórica 41 (2002-2004): 155-190; Ramos Sosa, "Retablos y esculturas," 397-422; Javier Chuquiray Garibay, La escultura en Lima en la primera mitad del siglo XVII (Lima: Museo de Arte Religioso de la Catedral de Lima, 2018). 
retablos de la época, pero queda un buen grupo de esculturas que dan testimonio de la calidad del trabajo colectivo encauzado por los maestros en sus talleres. Algunas de las cuales se encuentran atribuidas al mulato Juan Simón (Figs. 1 y 2 2 $^{60}$.

\section{Referencias}

\section{Fuentes documentales}

Archivo Arzobispal de Lima (AAL). Lima. Fondos: Cofradias; Testamentos del siglo XVII.

Archivo General de la Nación del Perú (AGN). Lima. Fondo: Protocolos notariales del siglo XVII.

\section{Fuentes bibliográficas}

Bernales Ballesteros, Jorge. "La escultura en Lima, siglos XVI-XVIII." En Escultura en el Perú, 1-134. Lima: Banco de Crédito del Perú, 1991.

Chuquiray Garibay, Javier. La escultura en Lima en la primera mitad del siglo XVII. Lima: Museo de Arte Religioso de la Catedral de Lima, 2018.

---. "El escultor Pedro Muñoz y la impronta de Gregorio Fernández en su obra limeña." En Pinceles y gubias del Barroco Iberoamericano, editado por María de los Ángeles Fernández Valle, Carme López Calderón, e Inmaculada Rodríguez Moya, 275-287. Vol. 7 de Universo Barroco Iberoamericano. Santiago de Compostela: Andavira Editora; Sevilla: Enredars/ Universidad Pablo de Olavide, 2019.

Cobo, Bernabé. Historia de la fundación de Lima. Lima: Imprenta Liberal, 1882.

Lima. Consejo Provincial. Libros de Cabildos de Lima. 23 Vol. Lima: Consejo provincial, 1935-1963.

Crespo Rodríguez, María Dolores. Arquitectura doméstica de la ciudad de los Reyes (1535-1750). Sevilla: Consejo Superior de Investigaciones Científicas, Escuela de Estudios HispanoAmericanos, 2006.

Gestoso y Pérez, José. Ensayo de un diccionario de los artífices que florecieron en Sevilla desde el siglo XIII al XVIII. Vol. 1. Sevilla: La Andalucía Moderna, 1899.

Harth-Terré, Emilio y Alberto Márquez Abanto. “El artesano negro en la arquitectura virreinal limeña." Revista del Archivo Nacional del Perú 25, no. 2 (1961): 3-73.

---. "Perspectiva social y económica del artesano virreinal en Lima." Revista del Archivo Nacional del Perú 26, no. 2 (1962): 353-446.

Harth-Terré, Emilio y Alberto Márquez Abanto. "Pinturas y pintores en Lima virreinal." Revista del Archivo Nacional del Perú 27, no. 1 y 2 (1963): 104-218.

60. Ramos Sosa, “El escultor Juan Simón," 42-44. 
Marco Dorta, Enrique. Fuentes para la historia del arte hispanoamericano. Estudios y documentos. Vol. 2. Sevilla: Consejo Superior de Investigaciones Científicas, 1960.

Mesa, José de, y Teresa Gisbert. Escultura Virreinal en Bolivia. La Paz: Academia Nacional de Ciencias de Bolivia, 1972.

Quiroz Chueca, Francisco. Gremios, razas y libertad de industria. Lima: Facultad de Ciencias Sociales Universidad Nacional Mayor de San Marcos, 1995.

---. Artesanos y manufactureros en Lima colonial. Lima: BCRP; IEP, 2008.

Quiroz Chueca, Francisco y Gerardo Quiroz Ch. Las ordenanzas de gremios de Lima (s. XVI-XVIII). Lima: Artes Diseño Gráfico, 1986.

Ramos Sosa, Rafael. "La pervivencia del manierismo en Lima. El motivo ornamental de la siIlería del monasterio de santa Catalina(1662)." En Actas IX Congreso español de Historia del arte (León 29 de setiembre a 2 de octubre de 1992), coordinado por el Comité Español de Historia del Arte, 445-448. León: Universidad, Secretariado de Publicaciones, D.L., 1994.

---. "La sillería coral de Santo Domingo de Lima." Archivo Español de Arte 68, no. 271 (1995): 309-316.

---. "Juan Martínez de Arrona, escultor (c. 1562-1635)." En Eskal Herria y el Nuevo Mundo: Ia contriución de los vascos a la formación de las Américas. VI Congreso Internacional de Historia de América, coordinado por Ronaldo Escobedo Mansilla, Ana Zaballa Beascoechea, y Óscar Álvarez Gila, 567-577. Vitoria: Universidad del País Vasco, 1996.

---. "Nuevas Noticias del escultor Bernardo Pérez de Robles en Perú." Revista del departamento de Historia del Arte, no. 16 (2003): 453-464.

---. "Una escultura de Martín Alonso de Mesa, el San Juan Evangelista de la Catedral de Lima (1623) y otras noticias." Histórica 27, no. 1 (2003): 181-206.

---. "El escultor-imaginero Gaspar de la Cueva en Lima (1620-1628)." En La consolidación del Barroco en la escultura andaluza e Hispanoamérica, coordinado por Lázaro Gila Medina, 425-443. Granada: Universidad de Granada, 2013.

---. "El escultor Juan Simón: discípulo y esclavo de Montañés." En Migraciones y rutas del Barroco, editado por Norma Campos Vera, 37-45. La Paz: Fundación Visión Cultural, 2014.

---. "Retablos y esculturas: El salomónico en Lima, 1650-1710." En El triunfo del Barroco en la escultura andaluza e Hispanoamérica, coordinado por Lázaro Gila Medina y Francisco Javier Herrera García, 397-422. Granada: Universidad de Granada, 2018.

---. "La fama de Montañés y su escuela en Hispanoamérica." En Montañés, maestro de maestros, coordinado por Ignacio Cano Rivero, Ignacio Hermoso Romero, y María del Valme Muñoz Rubio, 47-61. Sevilla: Junta de Andalucía, 2019. Catálogo publicado en conjunto con una exhibición del mismo título organizada y presentada en el Museo de Bellas Artes de Sevilla, 29 de noviembre de 2019-15 de marzo de 2020.

San Cristóbal, Antonio. "Nueva visión histórica de la sillería de la Catedral." Revista Histórica 33 (1981-1982): 221-268.

---. "Algunas sillerías corales limeñas." Revista del Archivo General de la Nación, no. 6 (1984): 71-100.

---. "El ensamblador arequipeño Juan Gutiérrez Coronado." Historia, no. 3 (1988): 255-280.

---. "El Ensamblador Tomás de Aguilar, natural de Nazca(1596-1666) y el Retablo-Sepulcro del arzobispo Arias de Ugarte." Histórica 38 (1993-1995): 177-215. 
---. "El ensamblador Mateo de Tovar y la evolución de los retablos en Lima." Boletín del Instituto Riva Agüero, no. 23 (1996): 241-286.

---. La Catedral de Lima. Estudios y Documentos. Lima: Museo de Arte Religioso de la Catedral de Lima, 1996.

---. "El carpintero mudéjar Antonio Velásquez." Revista del Archivo Nacional del Perú, no. 15 (1997): 155-197.

---. "Martín Alonso de Mesa y Juan García Salguero en el Retablo Mayor de la Concepción." Revista del Archivo General de la Nación, no. 17(1998): 91-130.

---. Arquitectura virreinal de Lima en la primera mitad del siglo XVII. Vol 1. Lima: Fondo Editorial FAUA, 2003.

---. La casa virreinal limeña de 1570 a 1687. Vol. 2 Lima: Fondo Editorial del Congreso del Perú, 2003.

---. "Las escuelas de los retablos virreinales." Histórica 41 (2002-2004): 155-190.

---. Nueva visión de San Francisco de Lima. Lima: IFEA; BCRP, 2006.

Siracusano, Gabriela. "Para copiar las 'buenas pinturas'. Problemas gremiales en un estudio de caso de mediados del siglo XVII en Lima." En Manierismo y transición al Barroco: memoria del III Encuentro Internacional sobre Barroco, editado por Norma Campos Vera, 131-139. La Paz: Unión Latina, 2005.

Villanueva, Carlos Alfonso. "Asencio de Salas: pecador público." Revista del Archivo General de la Nación, no. 15(1997): 133-153. 